\title{
Multi-residue levels of organophosphorus pesticides in cocoa beans from some cocoa farms in Ekiti state, Nigeria
}

\author{
O. A. Ibigbami ${ }^{1,2 *}$, A. F. Aiyesanmi ${ }^{1}$, E. I. Adeyeye $^{2}$, A. O. Adebayo ${ }^{1}$ and R. D. Aladesanwa ${ }^{3}$ \\ ${ }^{1}$ Department of Chemistry, The Federal University of Technology, PMB 704, Akure, Nigeria \\ ${ }^{2}$ Department of Chemistry, Ekiti State University, PMB 5363, Ado- Ekiti, Nigeria \\ ${ }^{3}$ Department of Crop, Soil, and Pest Management, The Federal University of Technology, PMB 704, Akure, Nigeria
}

\begin{abstract}
This study investigated the level and occurrence of 13 organophosphorus pesticides (OPPs) residues in cocoa beans from some cocoa farms in Ekiti state, Nigeria. The pesticides in the cocoa beans were extracted and cleaned up on silica gel adsorbent. A gas chromatograph coupled with flame photometric detector (FPD) was used to quantify the pesticides. The reliability of the analytical method was examined by spiking the beans with known concentration of the pesticides and analysed following similar procedure of extraction and clean-up. The percentage of pesticides recovered ranged from $88 \%$ to $92 \%$. Dichlorvos, mevinfos, diazinon, chlorpyrifos, dimethoate and parathion were detected with varying concentration in the bean samples whilst phosphamidon, pirimiphos-methyl, fenthion, bromophos, isofenfos, diclofenthion and ethion showed no detectable level. The concentration of OPPs ranged from ND - 58 $\mu \mathrm{g} / \mathrm{kg}$ and ND - $85 \mu \mathrm{g} / \mathrm{kg}$ for the dry and wet seasons respectively. Analysis of variance (ANOVA) showed no significant variation $(\mathrm{p}>0.05)$ in the levels of all detectable pesticides among the sampled farms whilst dichlorvos, diazinon, dimethoate and chlorpyrifos showed significant difference between both seasons. Residual levels of these detectable pesticides were below the maximum residue limits (MRLs) set by the European Union in food. Hence, the cocoa beans from the study areas are considered safe for consumption.
\end{abstract}

Keywords: Organophosphorus; Pesticides; Residue; Cocoa bean; Gas chromatography

\section{Introduction}

Cocoa (Theobroma cacao) is a small (4-8 $\mathrm{m}$ tall) perennial tree crop that primarily comes from three tropical regionsSoutheast Asia, Latin America, and West Africa. The cocoa fruit is an egg-shaped red to brown pod that contains $30-40$ seeds, each of which is surrounded by bitter-sweet white pulp. When the seeds are fermented and dried in the sun they are brownish red, and known as cocoa beans the principal ingredient of chocolate. Cocoa has a high food value as it contains as much as $20 \%$ protein, $40 \%$ carbohydrate, and $40 \%$ fat. It also contains theobromine, an alkaloid closely related to caffeine and phenols and flavenoids, antioxidants that can inhibit cancer and cardiovascular diseases. Cocoa beans are good sources of potassium, magnesium and iron. Nigeria is ranked fourth largest producer of cocoa beans in the world where cocoa is mostly grown in fourteen of the thirty six states. The size of cultivated area vary across states but an average cocoa farmer in Nigeria has a farm size of 2.5ha (Oguntade, 2003). On the whole, the average delivered per farmer in Nigeria is less than 5 bags per season (roughly $300 \mathrm{~kg}$ per hectare of cocoa) (Nwachukwu et al., 2010). Nigeria cocoa production depends on pesticides to attain acceptable levels of crop production. Hence, in obtaining good quality and high productivity of cocoa fruits, the cultivation of cocoa receive frequent application of various contact and systemic pesticides throughout the cropping season. Therefore, thousands of tonnes of pesticides (active ingredients) particularly OPPs are used annually, despite the ban in the use and production of OCPs globally. The present study aims at determining the levels and occurrence of thirteen OPPs (diazinon, mevinfos, dichlorvos, dimethoate, diclofenthion,phoshamidon,pirimiphos-methyl, chlorpyrifos,parathion,fenthion, isofenfos, bromophos and ethion) in cocoa beans from Ekiti state, south western Nigeria.

\section{Materials and methods}

Study area

The study area for the study covers eighteen cocoaproducing communities in Ekiti State, South-western Nigeria.

\footnotetext{
*Corresponding author e-mail: olayinkaibigbami@yahoo.co.uk
} 
They include Ijero, Aramoko, Ido-Ile, Ikoro, Igede, Esure, Ise, Emure, Orun, Igbara-Odo, Ilawe, Ilupeju, Ire, Ayedun, Ipawo, Usi and Ifaki. Ekiti state where the samples were collected lies between latitude $7^{0} 25^{1}-8^{0} 2^{1} \mathrm{~N}$ and longitude $5^{0} 00^{1}-6^{0} 00^{1}$ E. Ekiti State covers about $6,353 \mathrm{~km}^{2}$ land area. Fig. 1 shows the map of Ekiti State indicating the Local Government Areas where the samples were collected.

\section{Sample collection and preparation}

Four cocoa trees were randomly selected from each area of the farm where two ripe pods were harvested from each of the cocoa trees and combined to make composite samples. Three samples were collected in each farm making a total of 54 cocoa beans samples for each season. The beans were allowed to ferment for 3-5 days before being sun dried and dehulled, grind in agate mortar and later blended with Excella Mixer Blender (Kanchan International Limited) to fine particles. The samples were then packed in glass sample bottles prior to further analysis.
$\mathrm{Na}_{2} \mathrm{SO}_{4}$ were mixed together in a pre-cleaned $250 \mathrm{~mL}$ conical flask. Fifty millimeters $(50 \mathrm{~mL})$ mixture of acetone and n-hexane $(1: 1 \mathrm{v} / \mathrm{v})$ were mixed with the sample. This was followed by sonication in a high frequency ultrasonic bath for 10-15 minutes. The extract was then decanted into round bottom flask. The extraction process was repeated with additional $50 \mathrm{~mL}$ (acetone and $\mathrm{n}$-hexane mixture), sonicated and allowed to settle and decanted into the same round bottom flask. The combined extract was concentrated to $2 \mathrm{~mL}$ using a rotary evaporator. The extract was re-dissolved in 5 $\mathrm{mL} \mathrm{n}$-hexane and later concentrated to $2 \mathrm{~mL}$ in a rotary evaporator at $40{ }^{\circ} \mathrm{C}$.

The clean-up involved the use of a column of about $15 \mathrm{~cm}$ (length) $\mathrm{x} 1 \mathrm{~cm}$ (internal diameter) packed with $2 \mathrm{~g}$ of activated silica gel and $1 \mathrm{~g}$ anhydrous $\mathrm{Na}_{2} \mathrm{SO}_{4}$ on top of the silica gel (adsorbent). The column was conditioned with 15 $\mathrm{mL}$-hexane prior to clean up. The extract was introduced into the column and eluted with $20 \mathrm{~mL}$ of $\mathrm{n}$-hexane and

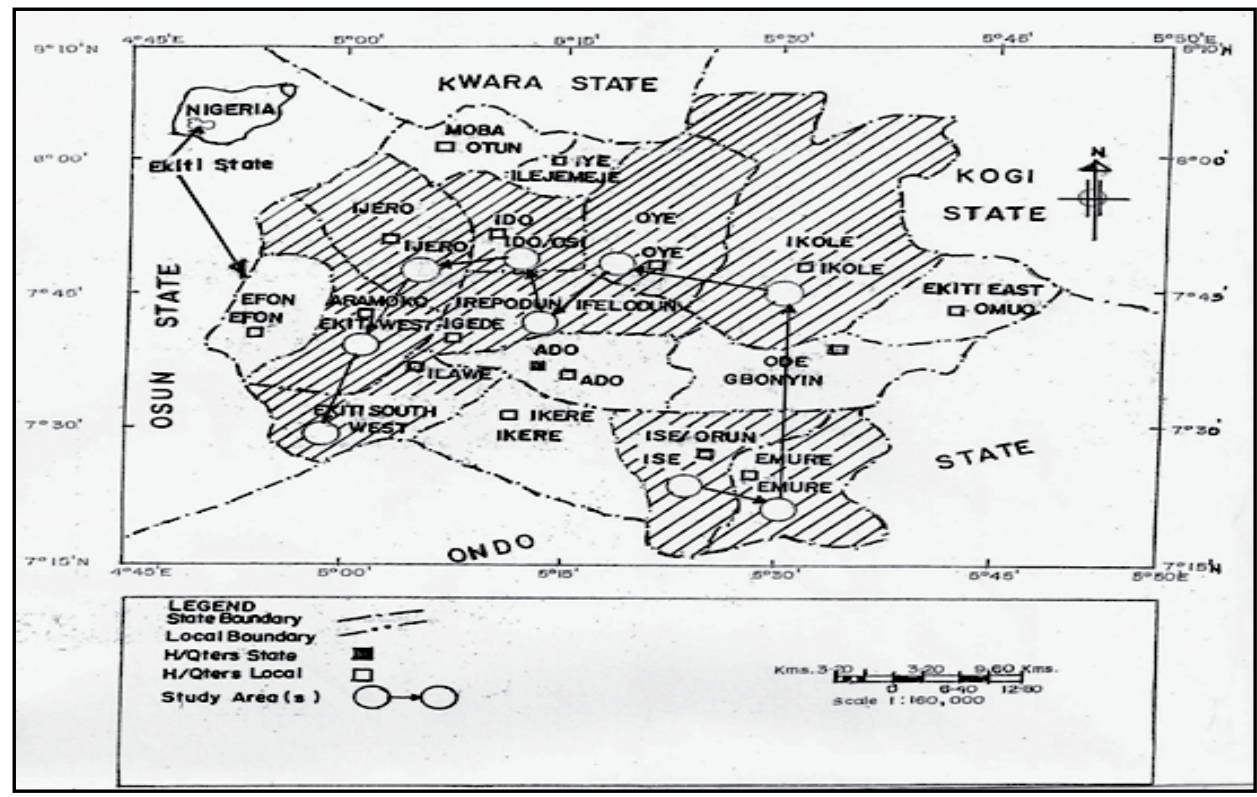

Fig. 1. Map of Ekiti State showing the position of the study areas

Source: Min. of Lands, Urban and Regional Planning, Ado-Ekiti/Dept. of Geography and Planning Science, Cartographic Unit, Ekiti State University (EKSU), Ado-Ekiti.

\section{Extraction procedure and clean-up}

Extraction of pesticides from cocoa beans samples was carried out by EPA 3550C method as described by USEPA (2000). About $20 \mathrm{~g}$ of each sample and $20 \mathrm{~g}$ of anhydrous diethyl ether $(1: 1 \mathrm{v} / \mathrm{v})$. The eluate was concentrated to dryness on the rotary evaporator and recovered into $2 \mathrm{~mL}$ n-hexane. The extract was transferred into glass GC vials for subsequent injection into the GC.The OPPs in the extracts were determined by a Gas Chromatograph (GC) coupled with flame photometric detector (FPD). 


\section{Gas chromatographic conditions}

The gas chromatography conditions for the analysis were as follows: GC model: Agilent 7693 Autosampler; the carrier gas flow rate was $2.7 \mathrm{ml} / \mathrm{min}$; Injector temperature: split injection: 20:1; carrier gas: nitrogen; inlet temperature: 250 ${ }^{0} \mathrm{C}$; column type: HP5 MS; column dimension: $30 \mathrm{~m} \mathrm{x} 0.32$ $\mathrm{mm} \times 0.25 \mu \mathrm{m}$; oven programme: initial temperature at $60^{\circ} \mathrm{C}$ for 1 minute, first ramping $10{ }^{\circ} \mathrm{C} / \mathrm{min}$ for $14 \mathrm{~min}\left(200{ }^{\circ} \mathrm{C}\right)$; maintained for $2 \mathrm{~min}$; second ramping at $10^{\circ} \mathrm{C} / \mathrm{min}$ for $8 \mathrm{~min}$ $\left(280^{\circ} \mathrm{C}\right)$; maintained for $3 \mathrm{~min}$; detector: flame photometric detector (FPD); detector temperature: $250^{\circ} \mathrm{C}$; hydrogen pressure: 22 psi; compressed air: 35 psi. The total run time was 28 minutes.

\section{Identification, quantification and quality control}

The validation of the analytical method was performed by the accuracy, precision, linearity, limit of detection (LOD) and quantification (LOQ). All the analysis was carried out using the same blank samples. Similar volume of solvents (n-hexane/acetone) and anhydrous sodium sulphate used in the extractions were subjected to similar extraction and clean-up procedures to detect any possible traces of the studied pesticides.

To determine the validity of the methodology, a recovery study was performed using standard addition method. Three samples were spiked with the mixture of pesticides standard solutions (1, 2 and $5 \mu \mathrm{g} / \mathrm{L})$. The spiked samples were allowed to stand for some hours and then extracted, cleaned up and analysed as described in the method above. The results showed that the mean recovery values ranged from 88 to $92 \%$. This indicated that the analytical procedures were reliable, reproducible and efficient. Precision of the method was evaluated through the relative standard deviation associated with pesticides measurements during recovery. Standard solutions of OPPs were run in GC-(FPD) under set chromatographic conditions and mean peak areas were plotted against concentrations to obtain calibration curves of individual pesticides. Stock solutions of organophosphorus (dichlorvos, mevinfos, diazinon, chlorpyrifos, dimethoate, diclofenthion, phosphamidon, pirimiphos-methyl, parathion, fenthion, isofenfos, bromophos and ethion) were prepare and stored in amber coloured bottles at $4^{0} \mathrm{C}$ in a refrigerator where working standard solutions were prepared fresh before use. Under the set chromatographic conditions, standard calibration curve was prepared for each OPP. The signatory retention time for each OPPs was used as confirmatory indicator. Linearity was determined by plotting calibration curve with standard solution in n-hexane containing four different concentrations $(0.1,0.25,0.5,1.0 \mathrm{ng} / \mu \mathrm{L})$.

The limit of detection (LOD) and quantification (LOQ) were calculated according to standard guidelines (Taylor, 1987; Saadati et al., 2013). All reagent used were of spectra purity.

\section{Statistical analysis of the data}

Data generated in the study were subjected to statistical analysis to test for spatial and seasonal variations with analysis of variance (ANOVA) using SPSS 15.0 package. One level of confidence limit $(p=0.05)$ was considered in the interpretation of the statistical results.

\section{Results and discussion}

Residues of dichlorvos, mevinfos, diazinon, dimethoate, chlorpyrifos and parathion were detected in the cocoa bean samples with varying concentration among the farm locations. The detected residues reflected the type of pesticide that has been used in the respective farm. The mean concentration of organophosphorus pesticide residues in the total samples were presented in Table I whilst Table II showed the level for both seasons. The concentration of OPPs in the cocoa beans samples ranged from ND - 58.1 $\mu \mathrm{g} / \mathrm{kg}$ with average concentration of ND - $10.8 \mu \mathrm{g} / \mathrm{kg}$ during the wet season whilst the dry season ranged from ND - $85.4 \mu \mathrm{g} / \mathrm{kg}$ with average concentration of ND $-5.96 \mu \mathrm{g} / \mathrm{kg}$. Six (6) OPPs were detected generally in the cocoa beans samples with concentration ranged of $0.79 \mu \mathrm{g} / \mathrm{kg}$ (parathion) to $85.4 \mu \mathrm{g} / \mathrm{kg}$ (diazinon) whilst phosphamidon, primiphos-methyl, fenthion, bromophos, isofenfos and ethion showed no detectable level.

The mean TOPPs in the samples ranged from $1.09-29.1 \mu \mathrm{g} / \mathrm{kg}$ for wet season while the dry season ranged from ND-36.9 $\mu \mathrm{g} / \mathrm{kg}$. Out of the total 108 cocoa beans samples, $59.2 \%$ contained dichlorvos, 5.56\%, 13.9\%, 11.1\% and $6.48 \%$ had mevinfos, diazinon, dimethoate and chlorpyrifos respectively while $0.92 \%$ contained parathion. The contamination levels of the beans using the mean organophosphorus pesticides were in the order: diazinon $>$ dichlorvos $>$ dimethoate $>$ chlorpyrifos $>$ mevinfos $>$ parathion whilst in terms of occurrence of the pesticides: dichlorvos $>$ diazinon $>$ dimethoate $>$ chlorpyrifos $>$ mevinfos $>$ parathion. The non-detectable OPPs in most of the beans samples 


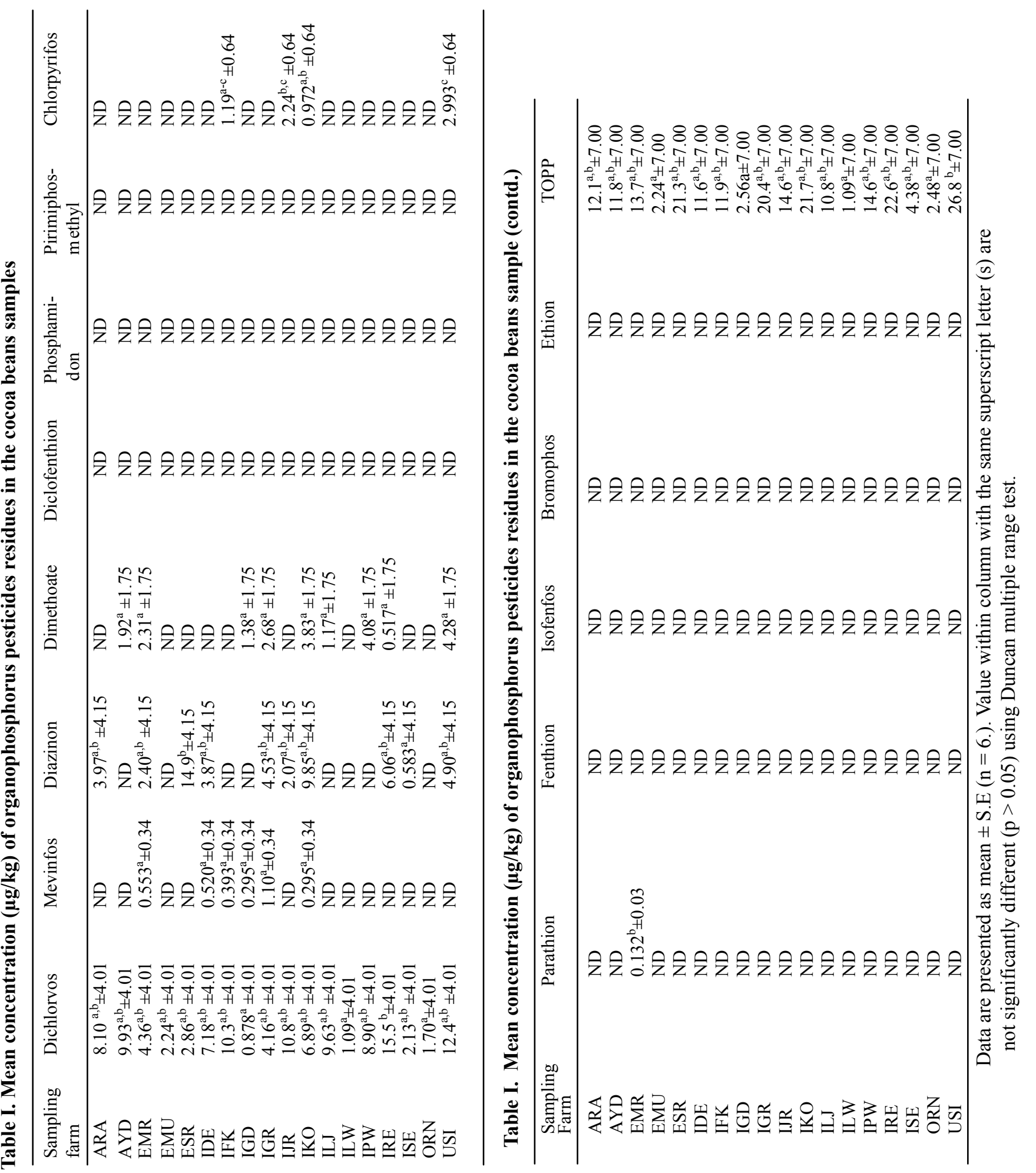



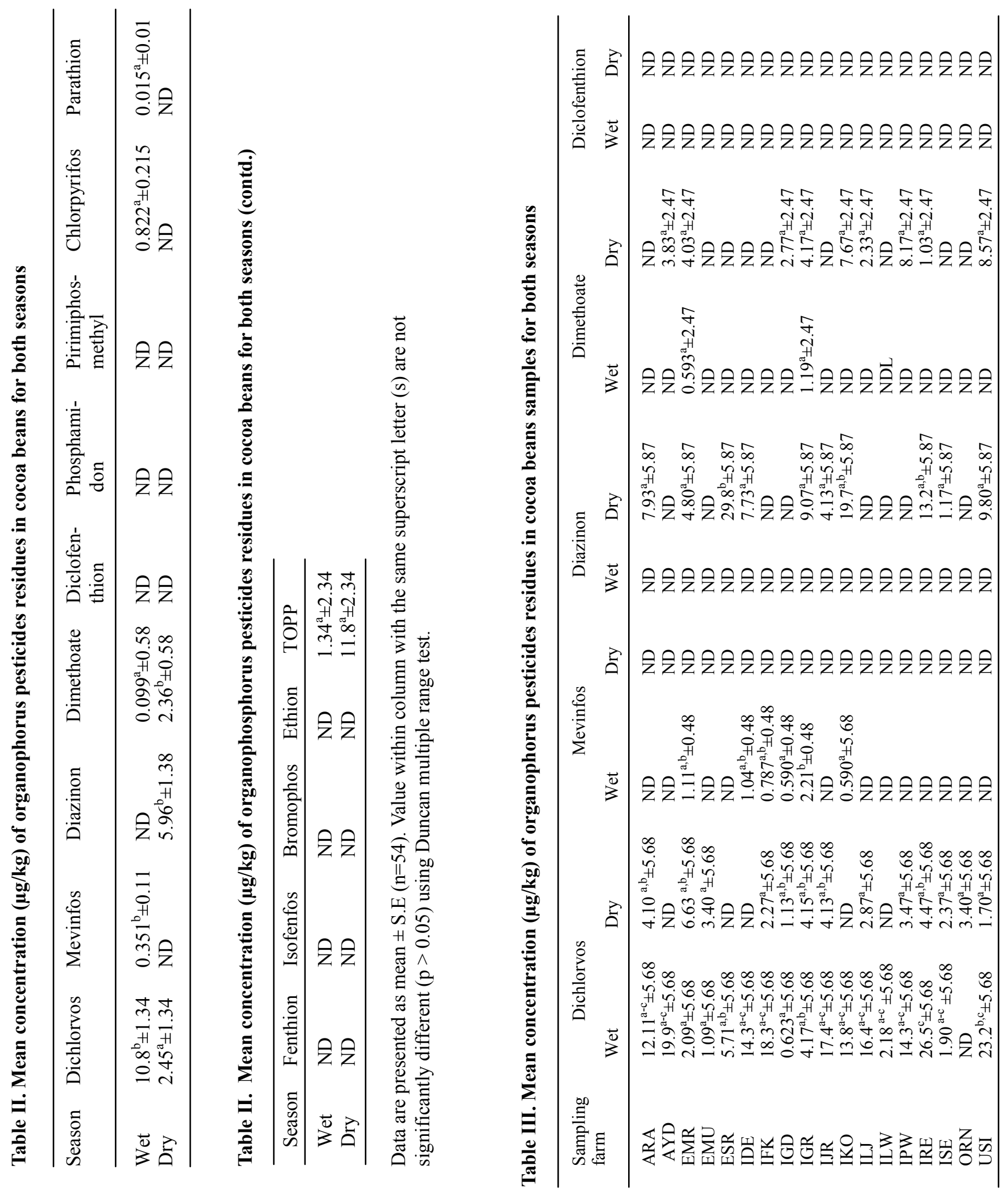

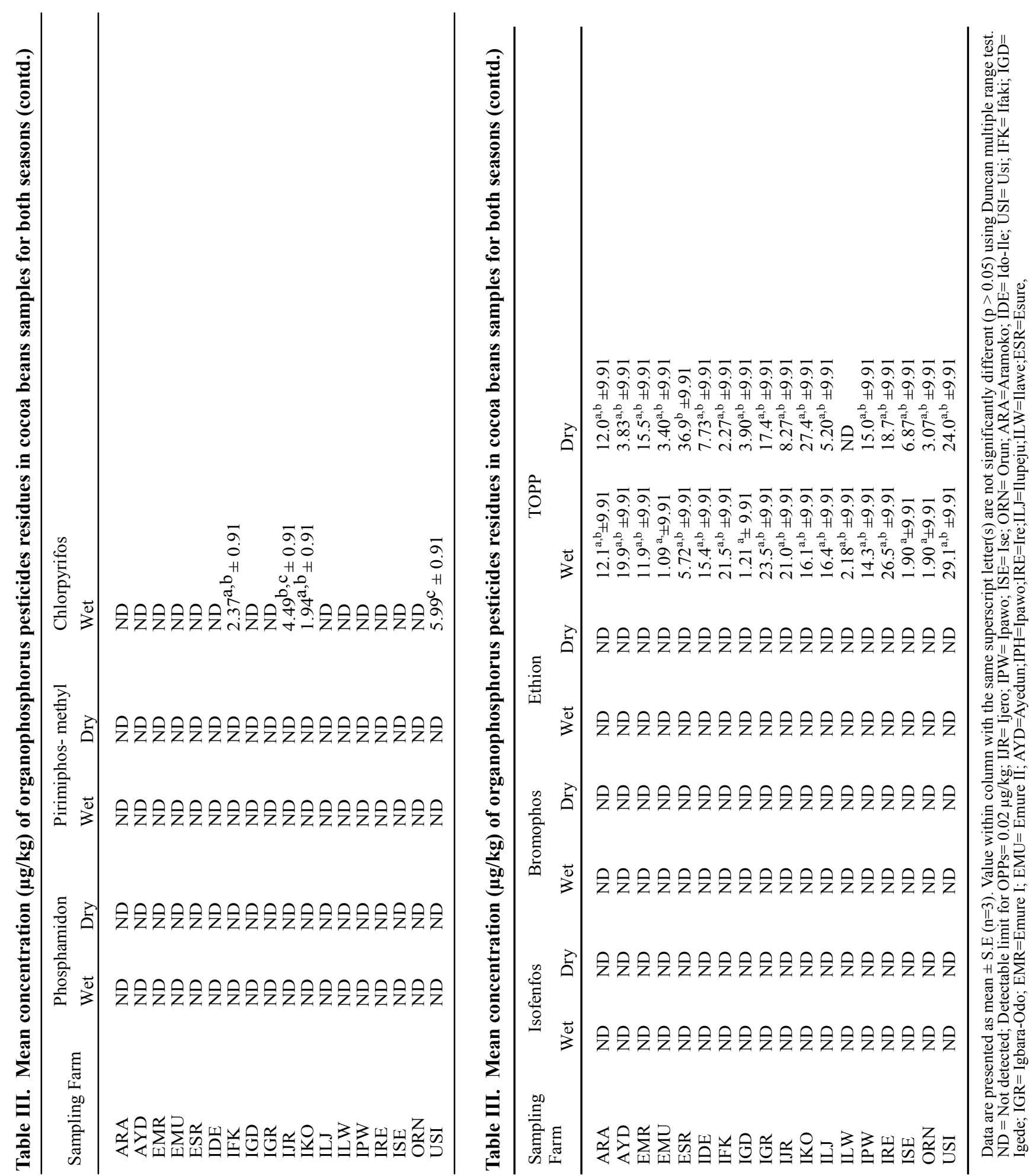
implies that these OP pesticides might have not been used on the study farms or possibly used and have degraded due low persistence and fast biodegradable nature of OPPs in the environment.

Dichlorvos mean concentration ranged from $0.878 \mu \mathrm{g} / \mathrm{kg}$ (IGD) to $15.5 \mu \mathrm{g} / \mathrm{kg}$ (IRE). For mevinfos, the mean concentration ranged from ND - $1.10 \mu \mathrm{g} / \mathrm{kg}$ (IGR). Mevinfos contaminations were in order: IGR $>$ EMU $>$ IDE $>$ IFK $>$ IKO $=$ IGD. Diazinon mean concentration ranged from ND - $14.9 \mu \mathrm{g} / \mathrm{kg}$. Diazinon contamination in the beans were in the order: ESR $>$ IKO $>$ IRE $>$ USI $>$ IGR $>$ IDE $>$ ARA $>$ EMU $>$ IJR $>$ ISE. The present study showed low level of diazinon as compared to the level reported by Aikpokpodion et al. (2012) where $40 \%$ of the cocoa beans from Ondo state contained diazinon with concentration range of non-detected to $170 \mu \mathrm{g} / \mathrm{kg}$ and average concentration of $120 \mu \mathrm{g} / \mathrm{kg}$ as compared to $13.9 \%$ in this study. The value reported in this study is comparably higher than those reported by Frimpong et al. (2012) in fermented dried cocoa beans samples from Tema and Tekoradi warehouses in Ghana. Aiyesanmi and Idowu (2012) reported a diazinon concentration of 117 $\mu \mathrm{g} / \mathrm{kg}$, the level that is significantly higher than those reported in this study. No sample exceeded EU MRL of $100 \mu \mathrm{g} / \mathrm{kg}$ for diazinon in food. The diazinon average residue concentration of $21.5 \mu \mathrm{g} / \mathrm{kg}$ is also below MRL EU (100 $\mu \mathrm{g} / \mathrm{kg}$ for diazinon) in food and CODEX (2005) maximum residue limit (MRL) for diazinon in food substances. However, despite this observation, the long term consumption of such trace concentrations in food substances have been implicated as the major source of chronic exposure to pesticide with residues now commonly found in human tissues. Diazinon have the tendency to accumulate in human system, this was confirmed by a study carried out by Sosan et al. (2008) where pesticides residues were found in six human blood serum. For dimethoate, mean concentration ranged from ND to $4.28 \mu \mathrm{g} / \mathrm{kg}$ (USI). The contamination pattern for dimethoate were in the order: USI $>$ IPW $>$ IKR $>$ IGR $>$ EMU $>$ AYD $>$ IGD $>$ ILJ $>$ IRE. The mean dimethoate level $(10.2 \mu \mathrm{g} / \mathrm{kg})$ recorded in this study is lower than (22.3 $\mu \mathrm{g} / \mathrm{kg})$ reported by Frimpong et al., (2012). The average concentration of dimethoate is below EU maximum residue limit $(50 \mu \mathrm{g} / \mathrm{kg})$ of dimethoate in food.
Chlorpyrifos showed detectable levels in four farms. The highest concentration $(13.1 \mu \mathrm{g} / \mathrm{kg})$ of chlorpyrifos was found in USI while IJR had the least $(3.64 \mu \mathrm{g} / \mathrm{kg})$. Chlorpyrifos contaminations were in order: USI $>$ IJR $>$ IFK $>$ IKO. The level of chlorpyrifos reported in this study was comparably lower than what was reported by Frimpong et al. (2012). All the samples collected were below EU MRL of $100 \mu \mathrm{g} / \mathrm{kg}$ for chlropyrifos in cocoa beans.

In general, phosphamidon, pirimiphos-methyl, fenthion, isofenfos, bromophos, diclofenthion and ethion proved not to have probably been used in cocoa production in Ekiti state. Considering the levels of OPPs residues in cocoa beans against the European Union showed that the cocoa beans produced in Ekiti will not pose any significant threat. OPPs residues above allowable limits in cocoa beans have potential detrimental effects on human health depending on the frequency of exposure and/or the potency toxicity of the pesticide (US EPA, 2000).

Analysis of variance (ANOVA) in SPSS 15 was used to assess the level of OPPs in the cocoa beans samples. The results showed no significant variation $(p>0.05)$ in the levels of all detectable pesticides except chlorpyrifos from the sampling farms. Seasonal variation showed no significant difference $(p>0.05)$ in parathion and TOPP whilst dichlorvos, mevinfos, diazinon, dimethoate and chlorpyrifos showed significant variation in both seasons.

\section{Conclusion}

The study revealed the presence of six (6) OPPs (dichlorvos, mevinfos, diazinon, dimethoate, chlorpyrifos and parathion) at varying concentration with diazinon and dichlorvos as highest concentration and the most occurring pesticides in the cocoa beans samples whilst phosphamidon, pirimiphos-methyl, fenthion, isofenfos, diclofenthion, bromophos and ethion showed no presence. The detectable pesticides showed low levels in the cocoa beans samples while most OP in the samples generally shows no detection. The levels of OPPs obtained in this study showed that the cocoa beans from this area are safe for consumption as none of the samples exceeded the European Union and Codex Alimentarius standards for the detectable OPPs in food. 


\section{References}

Aikpokpodion PE, Lajide L and Aiyesanmi AF (2012), Residues of diazinon and endosulfan in cocoa beans collected from three ecological zones in Nigeria, European Journal of Applied Sciences 4(6): 265-272.

Aiyesanmi AF and Idowu GA (2012), Determination of organophosphorus pesticide residue in some selected cocoa farms in Idanre, Ondo State, Nigeria, Electronic Journal of Environmental, Agricultural and Food Chemistry 11(2): 118-127.

CODEX (2005), Codex classification of Food and Animal feed (Codex Alimentrius) Pesticide residues in food, Rome.

Frimpong SK, Yeboah PO, Fletcher JJ, Pwamang J and Adomako D (2012), Multi-residue levels of organophosphorous pesticides in cocoa beans produced from Ghana, Elixir Food Science 47: 8721-8725.

Nwachukwu IN, Nnanna A, Jude N and George I (2010), Competitiveness and determinants of Cocoa Export from Nigeria.

Oguntade AE (2003), Cocoa value chain in Nigeria- past and present, Department of agricultural and resources Economics, Federal University of Technology, Akure.
Saadati N, Pauzi AM, Zakaria Z, Belm S and Sany T (2013), Limit of detection and limit of quantification development procedure for organochlorine pesticides analysis in water and sediment matrices, Chemistry Central Journal 7: 63-73.

Sosan MB, Akingbohungbe AE, Ojo IAO and Durosinmi MA (2008), Insecticide residues in the blood serum and domestic water source of cocoa farmers in south western Nigeria, Chemosphere 72: 781-784.

Taylor JK (1987), Quality assurance of chemical measurements, Lewis publishers, Chelsea, USA.

USEPA (2000), SW-846, testmethods for evaluating solid waste, $3^{\text {rd }}$ Ed., Update IVB. Chapter 4, Organic analytes, US EPA, Washington DC.

USEPA (2000), Assigning values to non-detected/ non-quantified pesticide residues in human health food exposure assessments, http:www.epa.gov/ pesticides/trac/science/trac3b012.pdf

Received: 04 August 2016; Revised: 18 January 2017;

Accepted: 29 May 2017. 